2. Петришин А. К вопросу использования полиэтилена в трубопроводах // Наука сегодня: задачи и пути их решения: мат. межд. научно-практ. конф. - Тюмень: Изд. ООО "Маркер", 2017. С.31-32.

3. Старостин Н.П., Аммосова О.А. Моделирование теплового процесса сварки полиэтиленовых труб встык при низких температурах // Инженерно-физический журнал. 2016. Том 89. №3. С. 706-713.

4. Стечкин С.Б., Субботин Ю.Н. Сплайны в вычислительной математике. М.: Наука, 1976. 248 с.

5. Библиотека FEniCS. http://fenicsproject.org/

6. Программа GMSH. http://geuz.org/gmsh/

\title{
Торопов В.П. \\ Проект устройства, отбирающего энергию у самого мощного природного аккумулятора - окружающего нас воздуха. Т.е. атмосферы Земли
}

doi: $10.18411 / l j-30-11-2017-62$

(Россия, Крьмм, п.Октябрьское)

idsp: 000001:lj-30-11-2017-62

Наша атмосфера обладает огромным количеством энергии. Полная энергия находится по формуле: $\mathrm{E}=$ Суд х $\Delta \mathrm{T}$ x m, где $\mathrm{E}$ - полная энергия, дж; Суд - теплоёмкость воздуха $=1000$ дж/кг град.; $\Delta \mathrm{T}-$ разница температур средней и нулевой нашей атмосферы 300-0 = 300 градусов Кельвина; m - масса нашей атмосферы, кг - очень большое число тонн. Всё это перемножается и получается очень большое число, практически равное бесконечности. А ещё существует закон сохранения энергии, открытый М.В. Ломоносовым: энергия не может из ничего возникнуть, а равно и никуда исчезнуть, она может только превратиться в другой вид. До сих пор считалось, от воздуха невозможно отнять энергию. Я же доказал, что возможно с помощью моего устройства. Оно по своей конструкции будет напоминать конструкцию газотурбинного двигателя с кое-какими изменениями. Меняются местами турбина и компрессор и вместо камеры сгорания установлен теплообменник.

Сади Карно, великий учёный прошлого, описал прямой цикл для теплового двигателя и обратный цикл для холодильных установок. Он брал теплоту от охлаждаемых тел. Не умаляю его работы, но я пошёл дальше его: разработал обратный цикл для теплового двигателя. Я же брал теплоту от потока воздуха после сжатия в компрессоре и поступающего через возвратную систему в теплообменник.

Сущность изобретения показана на схематическом чертеже Фиг.1.

1 - стартёр-генератор; 2 - вал устройства; 3 - турбина; 4 - теплообменник; 5 компрессор; 6 - возвратная система; 7 - выход воздуха.

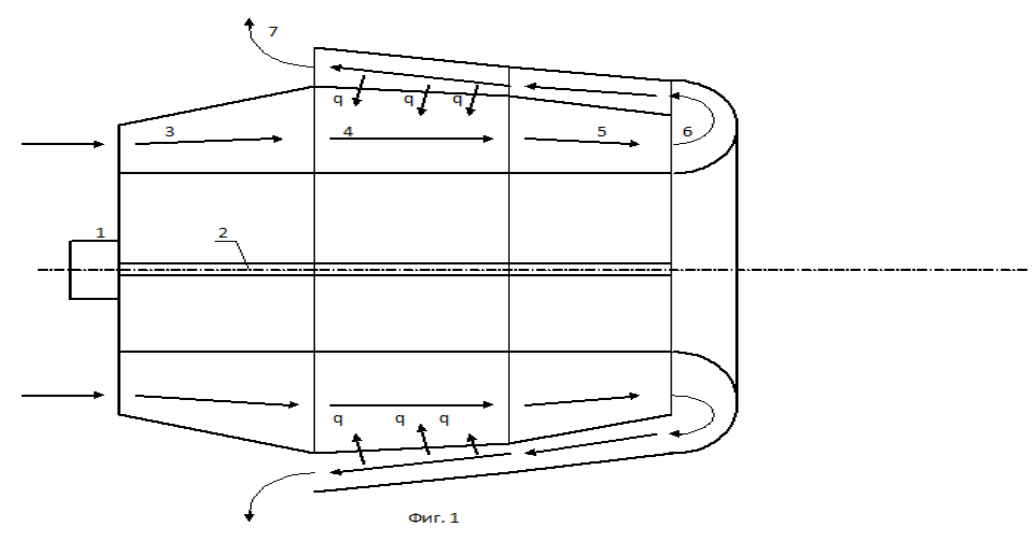

Устройство для преобразования воздушного потока работает следующци образом.

Вал устройства разгоняется стартер-генератором в режиме стартёра до оборотов, на которых работа, производимая турбиной, не станет больше затрачиваемой компрессором, на величину передачи теплоты в теплообменнике. Далее происходит переключение стартёр-генератора в режим генератора. Вал выходит на обороты малого 
газа. Оборотами руководит автоматическое устройство, заведённое на датчик оборотов вала. Обороты задаются натяжением пружины. При изменении оборотов на уменьшение, заслонка перекрывает щель перепуска воздуха, обороты увеличиваются. И, наоборот, при отклонении оборотов на увеличение, заслонка передвигается на открытие щели. Обороты уменьшаются. При включении нагрузки, щель перепуска воздуха прикрывается, и устройство выходит на режим заданных рабочих оборотов.

При вращении вала, компрессор работает как вакуумный и создаёт на входе разрежённую область, куда из атмосферы начинает стекаться воздух, проходя воздухозаборник, турбину и теплообменник. Возникает поток воздуха, подчиняющийся всем законам термодинамики. Проходя турбину, воздух в сопловом аппарате разгоняется до определённой скорости, при этом будут изменяться его параметры по закону адиабаты: скорость увеличиваться, давление и температура уменьшаться. Далее при проходе рабочего колеса воздух будет ещё расширяться, при этом давление и температура ещё упадут. Относительная скорость потока воздуха возрастёт. Абсолютная скорость упадет до определённых значений (относительная скорость будет складываться с линейной скоростью лопаток турбины), вызвав ещё падение давления и температуры. Пройдя все ступени турбины, поток изменит свои параметры: давление и температура понизится, объём увеличится.

Далее, имея пониженные температуру и давление, воздух поступает в теплообменник, где за счет естественного теплообмена будет получать от встречного потока воздуха, вернувшегося из-за компрессора, имеющего после сжатия воздуха повышенные температуру и давление, теплоту самопроизвольно. Воздух при нагревании будет расширяться по закону изотермы, т.е. в сужающемся канале, а, следовательно, и увеличивать свою скорость, тем самым восстановив потерянную кинетическую энергию на рабочем колесе турбины, которая передастся валу устройства. Далее воздух поступит на вход компрессора, где он будет по закону адиабаты сжиматься до атмосферного давления. После сжатия, воздух, проходя возвратную систему и перепускную заслонку, возвращается в теплообменник для отдачи своей теплоты самопроизвольно потоку воздуха после турбины, имеющего пониженную температуру, по отношению к потоку воздуха, вернувшегося после его сжатия. Процесс будет протекать по закону изотермы в расширяющемся канале. Отдавший часть теплоты воздух при давлении, равном атмосферному, выходит наружу, т.е. покидает устройство. Процесс закончен. В этом процессе будет учитываться одна особенность. При работе компрессора, как сжимающего, работа будет на графике зависимости давления от объёма располагаться между линией зависимости и осью объёма. При работе как вакуумного, работа тоже будет располагаться там же, но знаки поменяются на противоположные. Поэтому и работа устройства будет вычисляться:

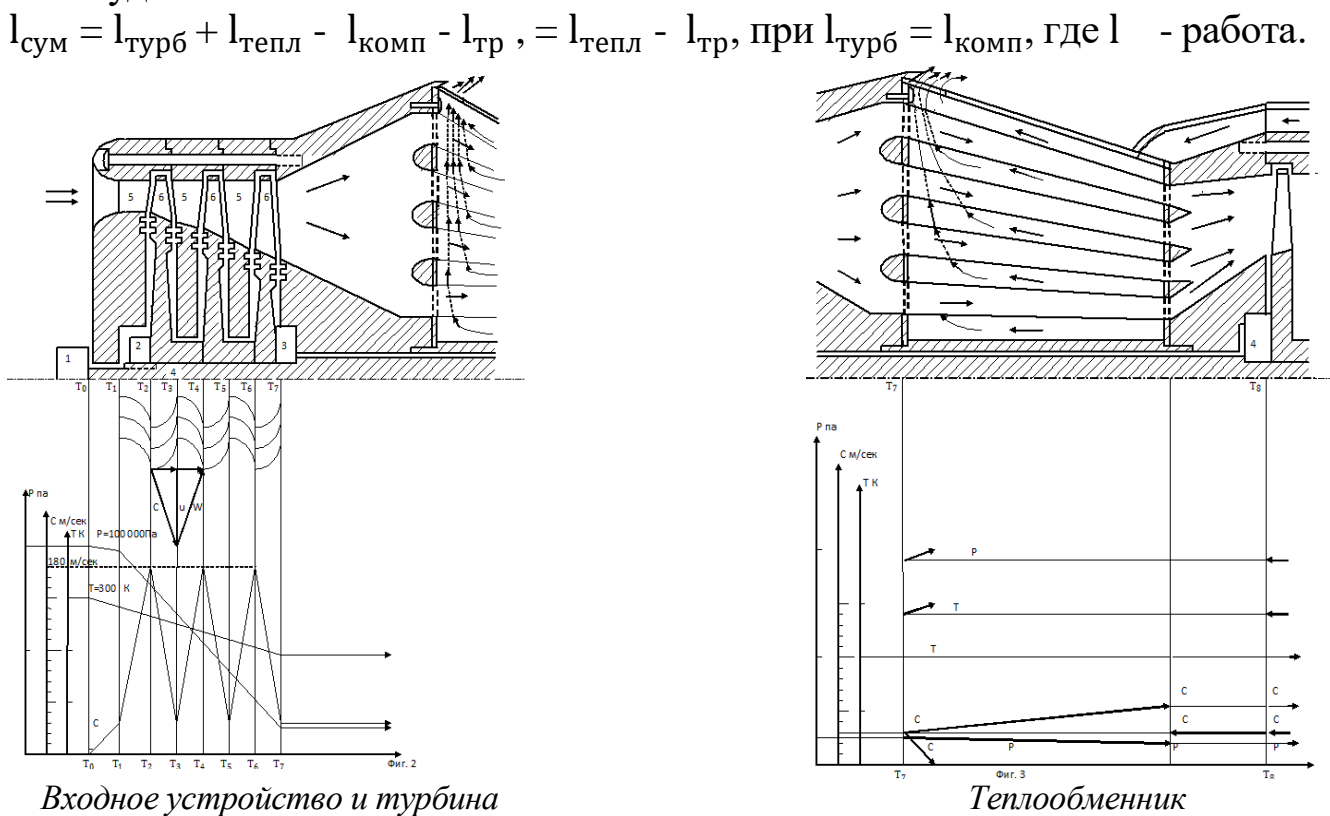




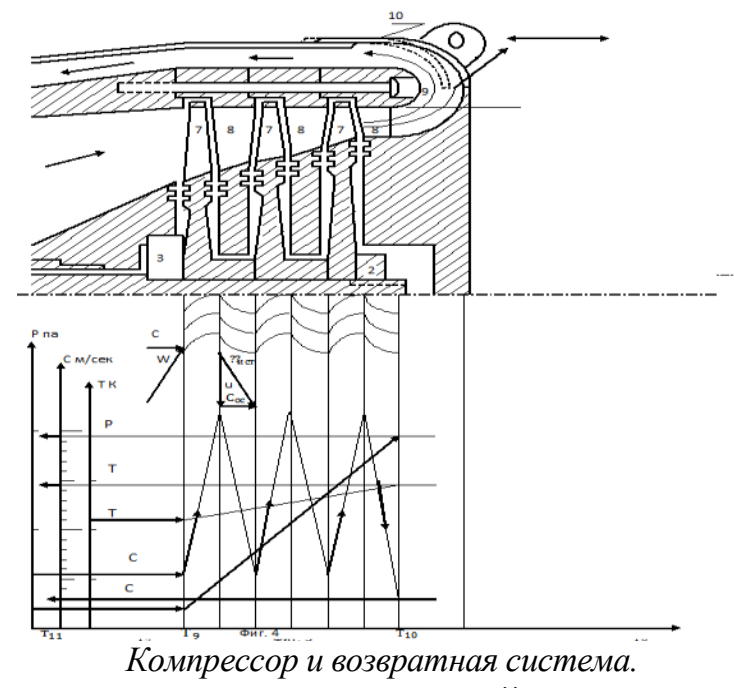

Фиг.2 - изображены в деталях входное устройство и классическая трёхступенчатая турбина, в которую входят лопатки направляющего аппарата 5 (сужающиеся каналы), лопатки рабочего колеса 6. Все процессы, протекающие в турбине, теплообменнике, диффузоре и осевом компрессоре рассчитаны согласно термодинамическим законам по отношению к воздушному потоку, возникшему при работе вакуумного компрессора. Стартёр-генератор при запуске работает в режиме стартёра. После выхода устройства на рабочие обороты стартёр-генератор переключается на режим генератора.

Фиг.3 - теплообменник, представляющий себя трубчатый противоточный воздуховоздушный радиатор. Мощность устройства будет зависеть от площади теплообмена в теплообменнике, разности температур потоков воздуха после турбины и после сжатия воздуха в компрессоре, способа теплообмена (попутными потоками, поперечным обдувом и противотоком).

Фиг.4 - вакуумный осевой компрессор (лопатки рабочего колеса 7 и лопатки спрямляющего аппарата 8) и возвратная система 9 с перепускной заслонкой 10 для автоматической регулировки оборотов (мощности), заведённой на датчик оборотов. При увеличении мощности будут падать обороты, но датчик установит заслонку в положение, более прикрывающее перепуск воздуха в атмосферу, теплообмен увеличится. Обороты снова станут заданными. Осевой компрессор представляет себе трёхступенчатый классический компрессор с рабочим колесом и спрямляющим аппаратом. Последняя ступень рассчитана с условием прироста кинетической энергии потока воздуха в теплообменнике. Несколько ниже изображены профили лопаток. Ещё ниже - графики зависимости параметров воздушного потока: Р па, С м/сек, Т Кельвин, от прохождения той или иной части устройства.

1. Б.Н. Юдаев. Техническая термодинамика. Теплопередача. Москва «Высшая школа». 1988 г. 479 стр.

Чернышова В.А., Салахова А.Ф., Ахмерова Г.М.

Способы продления срока службы подземных теплопроводов систем теплоснабжения

Казанский государственный архитектурно-строительный университет (Россия, Казань)

doi: $10.18411 / l j-30-11-2017-63$

idsp: 000001:lj-30-11-2017-63

\section{Аннотация}

Срок службы подземных теплопроводов систем теплоснабжения может быть снижен по причинам использования устаревших технологий при строительстве 